\title{
Recurrent haemorrhage from cerebral aneurysms and its prevention by surgery ${ }^{1}$
}

\author{
M. R. CROMPTON \\ From the Neurosurgical Department of St. George's Hospital at Atkinson Morley's Hospital, and the Depart- \\ ment of Pathology, St. George's Hospital, London
}

A patient who survives the rupture of a cerebral berry aneurysm is very likely to suffer yet another haemorrhage from that aneurysm within the subsequent six weeks, and especially within the first two weeks (McKissock, 1956; McKissock, Paine, and Walsh, 1960). This is in marked contrast to primary or hypertensive intracerebral haemorrhage and bleeding from an angioma, which, though they may recur, do so at much longer intervals. There is also evidence that second and subsequent haemorrhages from an aneurysm are more likely to rupture directly into the brain with a correspondingly more lethal effect than a purely subarachnoid haemorrhage (Crompton, 1962). Surgery to prevent recurrent haemorrhage from an aneurysm carries a high mortality in the first few weeks after the initial haemorrhage, but this is the time when it is most urgently required. If it is performed later, the mortality is considerably less, but so also is the danger of recurrent haemorrhage. Thus an essentially prophylactic procedure loses a great deal of its point when it is delayed. It was with these facts in mind that a series of necropsies on patients dying after rupture of an aneurysm was examined to assess any detectable feature associated with early recurrent haemorrhage, and also to determine the effect of the various surgical procedures designed to prevent recurrent haemorrhage.

Recurrent haemorrhage was arbitrarily defined as a further haemorrhage from an aneurysm within six weeks of the haemorrhage which necessitated the patient's admission to hospital. Criteria for this consisted of good neurological evidence of recurrent haemorrhage with fresh blood in the cerebrospinal fluid on lumbar puncture or a necropsy soon after the recurrent haemorrhage, when slightly altered blood from the previous haemorrhage would be found. Cases in which there was any doubt were excluded.

Using these criteria there were adequate data for

${ }^{1}$ This paper is a condensation of part of a Ph.D. thesis submitted to London University in 1965. information to be collected on 173 cases in which no surgery was performed or directed at any cerebral aneurysms, and 105 cases in which surgery was directed at the ruptured aneurysm. These 278 cases were from a consecutive necropsy series of 289 patients dying following the rupture of a cerebral berry aneurysm.

\section{RESULTS IN CASES NOT TREATED SURGICALLY}

ANEURYSM DISTRIBUTION Table I shows the distribution of the aneurysms in the 173 patients and theo frequency of recurrent haemorrhages in the whole series and in relation to the sites of the aneurysms. It can be seen that approximately one half, 89 , of the conservatively treated or untreated cases coming to necropsy have had a recurrent haemorrhage within six weeks of the haemorrhage necessitating admis sion. This applies to the aneurysms at the differen sites, with the possible exception of aneurysms of the internal carotid at the origin of the posterior communicating and anterior choroidal arteries when grouped together. These aneurysms appeared to cause recurrent haemorrhages more frequently than those at other sites, but the difference is not of statistical significance with these figures.

\section{TABLE I}

FREQUENCY OF RECURRENT HAEMORRHAGES FROM ANEURYSMS AT DIFFERENT SITES IN 173 NON-SURGICAL CASES

$\begin{array}{lll} & \text { No. with } & \text { No. without } \\ \text { Aneurysm Site } & \text { Recurrent } & \text { Recurrent } \\ & \text { Haemorrhages } & \text { Haemorrhages }\end{array}$

Anterior communicating and

anterior cerebral

Middle cerebral

Posterior communicating and

anterior choroidal

Vertebro-basilar

Internal carotid bifurcation

Ophthalmic origin Total

$\begin{array}{rr}37 & 37 \\ 17 & 20 \\ 23 & \\ 6 & 15 \\ 4 & 6 \\ 2 & 5 \\ 89 & 1 \\ & 84\end{array}$

SEX AND AGE DISTRIBUTION Sex and age distribution in relation to recurrence are shown in Table II and 
TABLE II

SEX DISTRIBUTION IN CASES WITH AND WITHOUT RECURRENT HAEMORRHAGE

\begin{tabular}{|c|c|c|}
\hline & $\begin{array}{l}\text { No. with Recurrent } \\
\text { Haemorrhage }\end{array}$ & $\begin{array}{l}\text { No. without Recurrent } \\
\text { Haemorrhage }\end{array}$ \\
\hline Males & $\begin{array}{l}34 \\
(38 \%)\end{array}$ & $\begin{array}{l}37 \\
(44 \%)\end{array}$ \\
\hline Females & $\begin{array}{l}55 \\
(62 \%)\end{array}$ & $\begin{array}{l}47 \\
(56 \%)\end{array}$ \\
\hline
\end{tabular}

Fig. 1. There was no significant difference in sex incidence but a relatively greater proportion of patients died in the fourth and seventh decades amongst those with recurrent haemorrhages.

MULTILOCULATION In 47 of 86 cases with recurrent haemorrhage, in which the ruptured aneurysm could be examined, it was multiloculated. This was a similar proportion to 44 multiloculated ruptured aneurysms amongst 77 cases without recurrent haemorrhages.

THROMBOSIS OF ANEURYSMS The proportion of cases with thrombosed aneurysms at necropsy was similar in the cases with recurrent haemorrhages, $29 \%$, and in the cases without recurrent haemorrhages, $32.5 \%$. Of the 25 thrombosed aneurysms amongst the 86 cases with recurrent haemorrhages, nine were completely filled with thrombus and the rest were only partially filled, while of the 26 thrombosed aneurysms

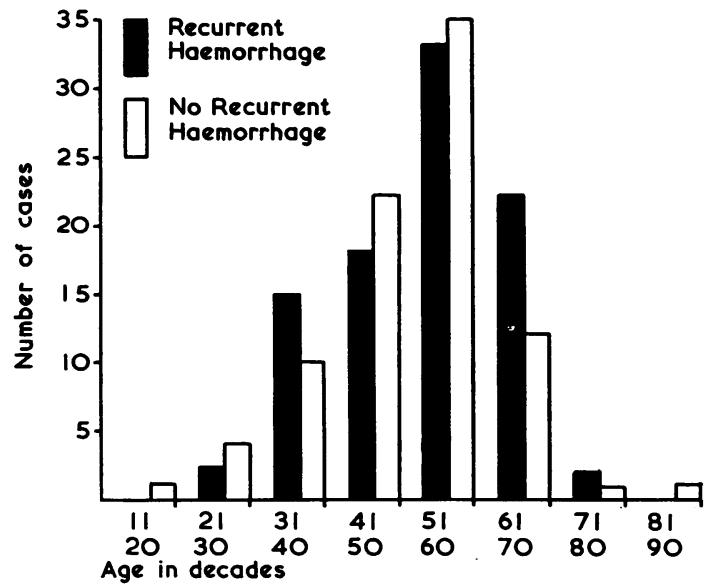

FIG. 1. The age distribution in 89 patients with, and in 84 patients without, recurrent haemorrhage.

amongst the 80 cases without recurrent haemorrhages, there were 12 completely filled.

This partial thrombosis in the aneurysms was usually mural in the fundus and always formed a laminated plug that extended to fill the rupture and sometimes extended outside the rupture as a fungating reddish or whitish-red knob (Fig. 2). This often gave the appearance of an additional loculus to the

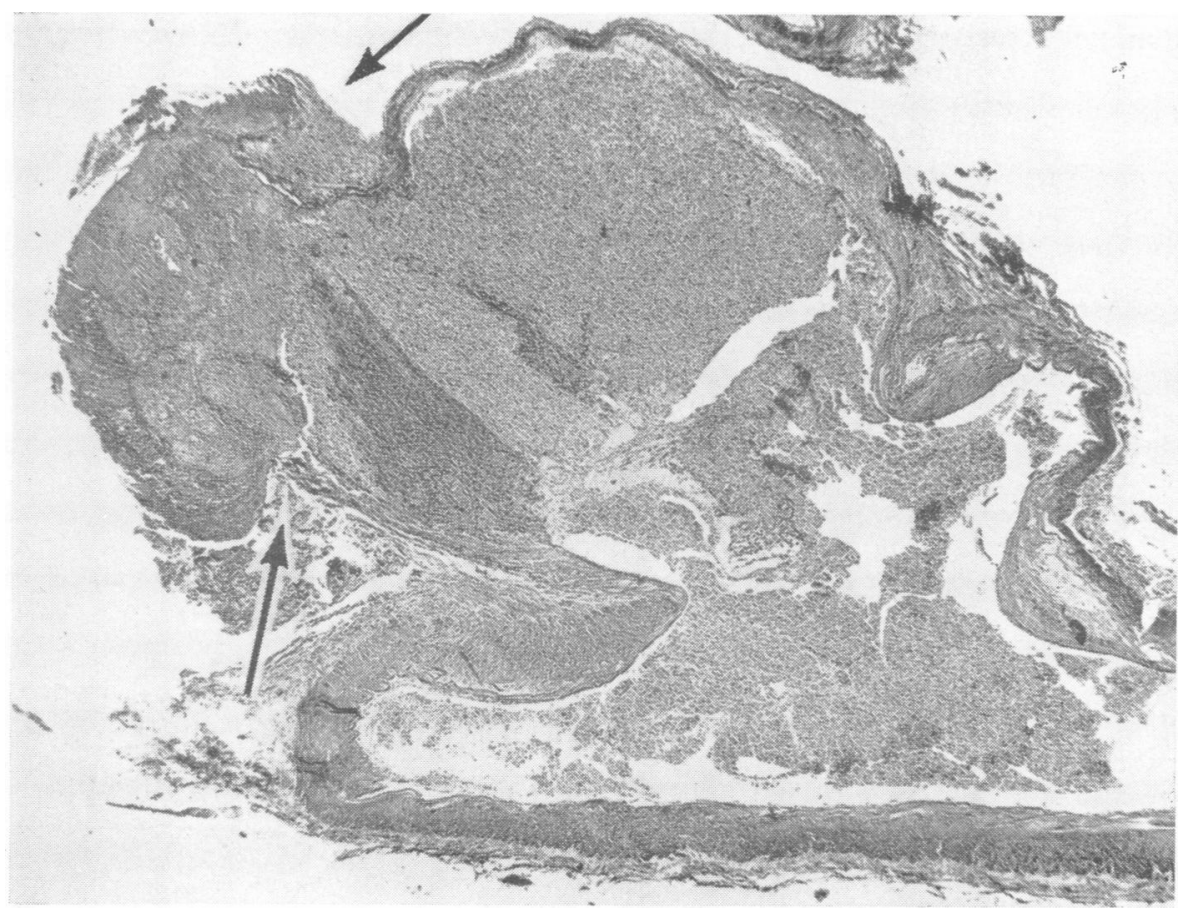

FIG. 2. A plug of thrombus (between arrows) is extruding from a rupture in an aneurysm. Laminated mural thrombus is also present in the lower part of the sac. Picro-Mallory $\times 36$. 


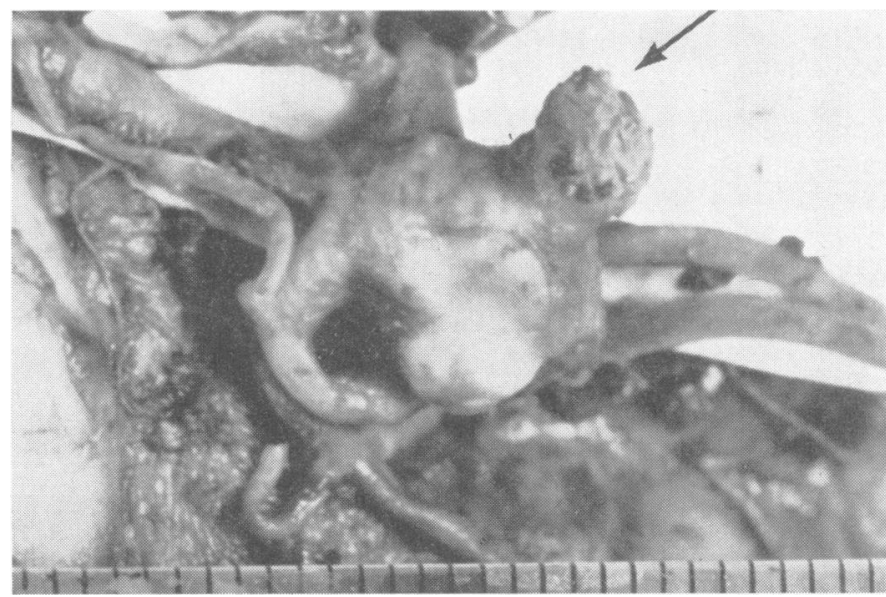

FIG. 3. A middle cerebral aneurysm with a fibrin-platelet plug (arrowed) extruding from the point of rupture.

aneurysms (Fig. 3) until histology showed it was not part of the aneurysm but a plug consisting almost completely of material which stained like platelets with the picro-Mallory stain, together with some laminated fibrin. Red cells were few. The structure of this plug suggested that the conglutination of platelets was an important factor in sealing the rupture in an aneurysm and stopping bleeding.

Recurrent haemorrhages always appeared to occur through the original rupture, and so must have broached the platelet fibrin plug which formed after the first rupture.

Recent thrombus does not necessarily prevent an aneurysm from bleeding again soon, but there are difficulties in making certain whether thrombus has formed before or after a recurrent haemorrhage, especially as organization may develop slowly in thrombosed aneurysms (Crawford, 1959a). In some cases, however, the presence of early organization provides good evidence that mural thrombosis has occurred and that recurrent haemorrhage has developed subsequently by breaking through or dissecting around the thrombus. Foamy phagocytes and cholesterol clefts, suggesting atheroma, appear remarkably early in the larger thrombi in aneurysms, even while morphologically intact red cells are still present.

SIZE OF ANEURYSM FUNDUS Figure 4 shows the maximum external diameter of the sac or fundus of the cases which had recurrent haemorrhages, compared with those that did not have recurrent haemorrhages. It can be seen that those with recurrent haemorrhages had a greater proportion of sacs with a maximum external diameter around $10 \mathrm{~mm}$. than did the cases with no recurrent haemorrhages, in which there was a predominant concentration of sacs with a maximum external diameter around
$5 \mathrm{~mm}$. These differences are suggestive but not statistically significant. They do not affect one sex more than the other.

SHAPE OF THE ANEURYSM FUNDUS It is extremely difficult to compare shapes, especially the shapes of berry aneurysms which may be quite bizarre. An attempt, however, was made by taking the drawings़्त of the inferior view of the aneurysms of the last $37_{\bar{C}}$ consecutive cases amongst those with recurrente haemorrhages and placing them together on a page? in contrast with the drawings of the last 37 con 8 secutive cases without recurrent haemorrhage (Fig. 5). The reader is asked to state what his visuab. $\vec{\otimes}$ impression is of the two groups on either side of the central line. They should be viewed as a whole, and individual aneurysms should not be picked out

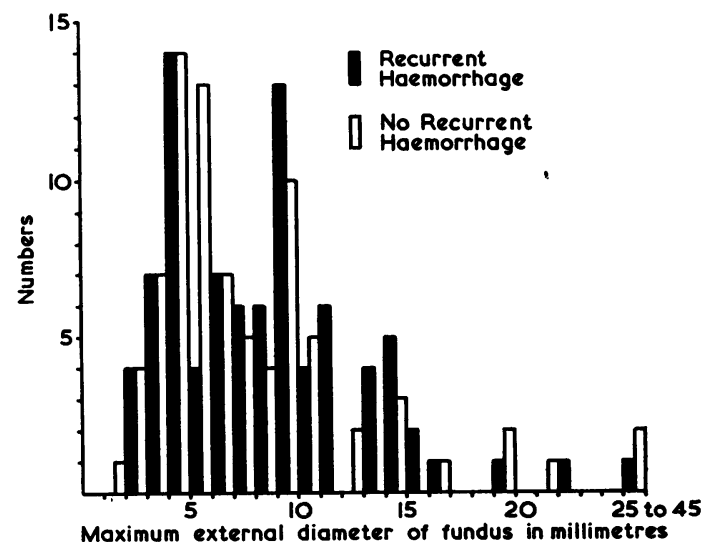

FIG. 4. The maximum external diameter of the fundus in 89 cases with, and in 84 cases without, recurrent haemorrhage. 


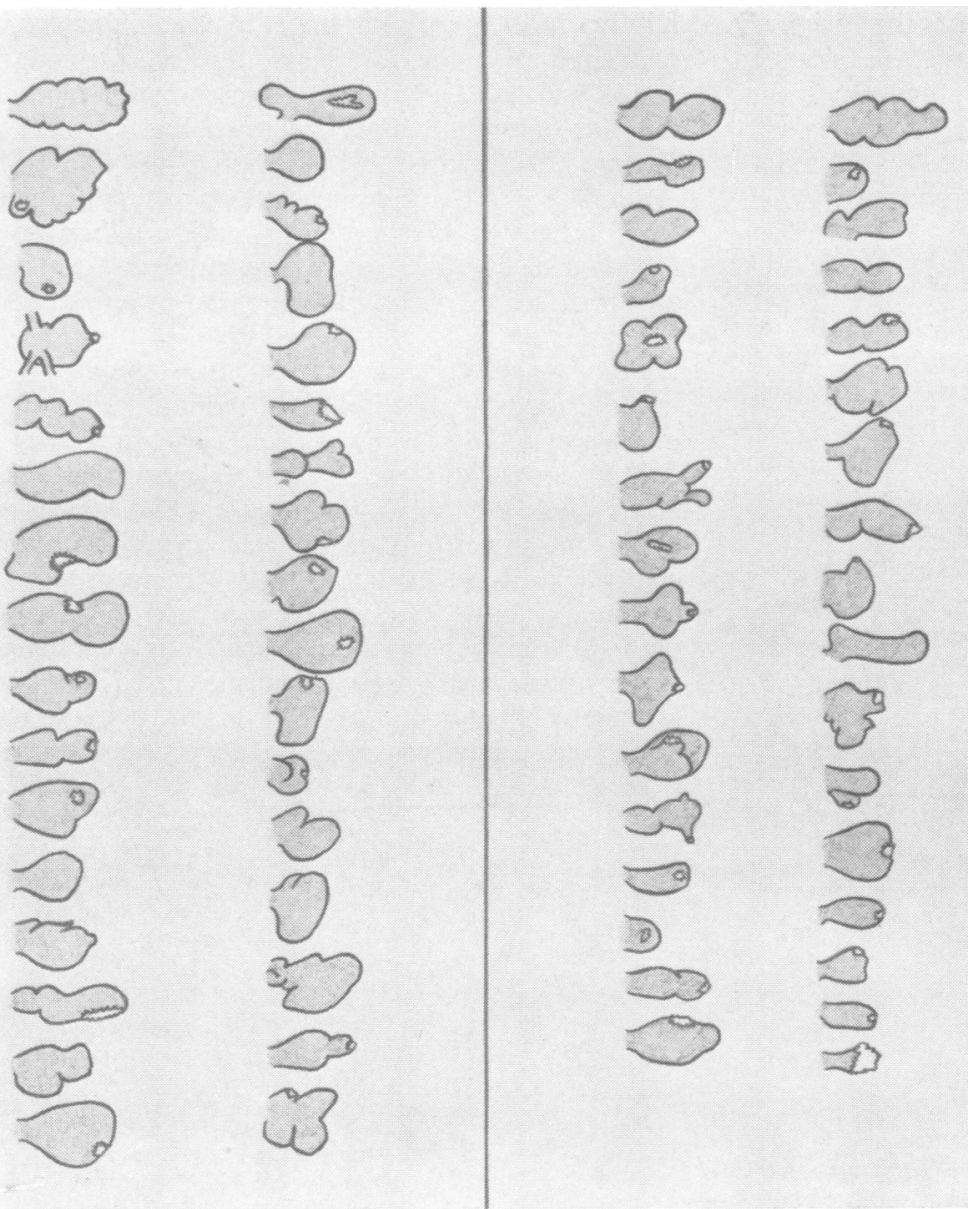

FIG. 5. Drawing to show the shape of aneurysms in which recurrent haemorrhage occurred (on the left) and those in which no recurrent haemorrhage occurred (on the right).

visually. The drawings are not to scale and comparative size should be ignored. I consider that the aneurysms to the left of the centre line were plumper or more pear-shaped than those on the right, which tended to be longer and more tubular. Obvious individual exceptions can be picked out, but this was the general impression. The aneurysms on the left were those in which recurrent haemorrhages occurred, those on the right were from cases without recurrent haemorrhages.

These findings on the size and shape of aneurysms in cases with and without recurrent haemorrhages are not conclusive, but they suggest that the larger more pyriform or globular aneurysms may be more likely to cause recurrent haemorrhages than the smaller or the longer, more tubular aneurysms.

HYPERTENSION It is not always possible to establish with certainty at necropsy that a patient has suffered from chronic hypertension, but in general, established hypertensive subjects have a heart weight in excess of $375 \mathrm{~g}$. and left ventricular muscle thickness of $20 \mathrm{~mm}$. or more. In 66 cases with recurrent bleeding, $37(56 \%)$ had heart weights over $375 \mathrm{~g}$. while 17 $(35 \%)$ of 49 cases with recurrent bleeding, in which the measurement was recorded, had ventricular thickness of $20 \mathrm{~mm}$. or more. The corresponding figures for cases without recurrent bleeding were 27 $(52 \%)$ of 52 cases with increased heart weight and 21 $(44 \%)$ of 48 cases with increased ventricular muscle thickness. These figures afford no evidence that hypertension is a factor in leading to recurrent haemorrhage.

HAEMORRHAGE FROM MORE THAN ONE ANEURYSM In the patients with multiple aneurysms, recurrent haemorrhages within six weeks of the haemorrhage necessitating admission were always from the originally ruptured aneurysm. In three of the 105 patients treated surgically, a second aneurysm 
ruptured following obliteration of the originally ruptured aneurysm by clipping, but this recurrent haemorrhage was always considerably later than six weeks after the original haemorrhage.

\section{RESULTS IN CASES TREATED SURGICALLY}

Table III shows the number of cases operated upon in different ways in the 105 cases which underwent surgery directed at the aneurysm. Clipping and obliteration of the aneurysm sac or neck renders thrombosis irrelevant but it may be a relevant factor in those operations in which the aneurysm is wrapped with cotton gauze, one anterior cerebral stem proximal to an anterior communicating aneurysm is clipped or the common carotid artery is ligated. The recurrent haemorrhages recorded in the last column are those occurring within six weeks of the 'admission haemorrhage'. The majority of the cases were operated upon within two or three days of admission.

TABLE III

RESULTS OF SURGERY

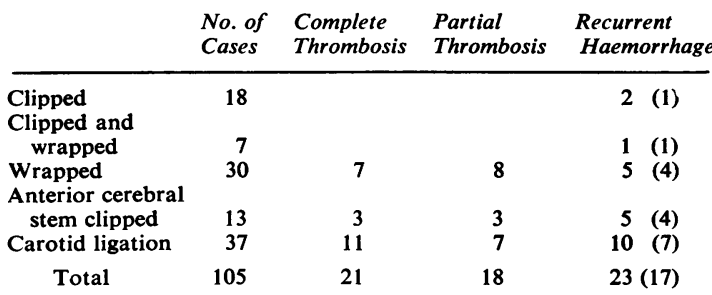

Two cases were not included in Table III. In one a proximal clip was placed on the left vertebral artery for an aneurysm at the origin of the left posterior inferior cerebellar artery, and in another a left middle cerebral aneurysm was excised.

In the last column in the table, the figures in brackets represent the number of cases in which recurrent haemorrhage occurred after surgery had been directed at the correct aneurysm, that is, the one which was shown at necropsy to have ruptured. Thus this figure represents the true failures of that method of surgery. The figure which is not in brackets includes cases in which surgery was directed at the wrong aneurysm, that is, at unruptured aneurysms in cases of multiple aneurysms.

The one failure associated with clipping occurred when a clip was applied to a ruptured middle cerebral aneurysm but did not pass right across the sac. The aneurysm had bled past the clip and out of the original rupture. One anterior communicating aneurysm bled again in spite of two clips on its fundus and gauze wrapping. The point of rupture could not be definitely assessed. There were four failures following wrapping, the aneurysms having bled again from the original rupture and through the gauze wrapping. Recurrent haemorrhage from an anterior communicating aneurysm had occurred in the four failures following clipping of the anterior cerebral stem. In the seven cases of failure after carotid ligation the operation had been performed for anterior communicating aneurysms in four cases and for a middle cerebral aneurysm in one case.

LONG-TERM EFFECTS OF SURGERY In a few cases there was an opportunity to observe the long-term effects of surgery.

In one case the left intracranial vertebral artery was occluded by a clip just proximal to an aneurysm arising at the origin of the left posterior inferior cerebellar artery. This aneurysm had ruptured and on angiography it had a maximum internal diameter of $6 \mathrm{~mm}$. Surgery was performed one year before death, and at necropsy, the aneurysm had a maximum external diameter of only $3 \mathrm{~mm}$. and its wall was thick and collagenous around a very small lumen (Fig. 6).

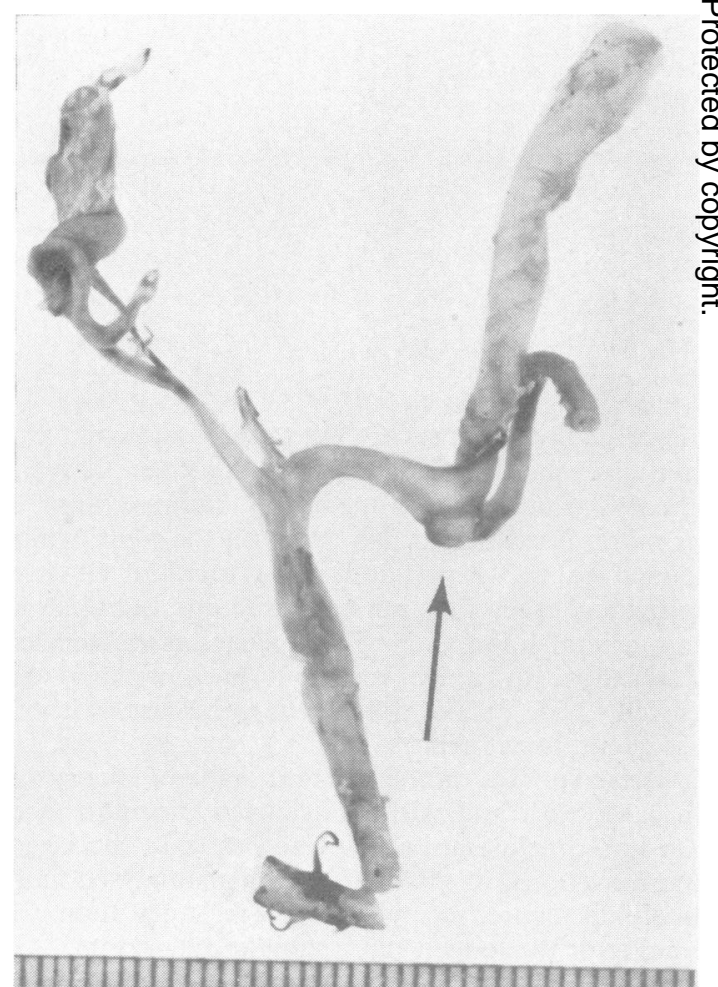

FIG. 6. A sclerosed aneurysm at the origin of the posterior inferior cerebellar artery. A clip occludes the vertebral artery proximal to it. 
In another case a ruptured left anterior choroidal aneurysm was seen on angiography to have a maximum internal diameter of $4 \mathrm{~mm}$. Left common carotid ligation was performed. Death occurred five years later following rupture of a right posterior communicating aneurysm, and at necropsy, the previously ruptured left anterior choroidal aneurysm was seen to have a maximum external diameter of only $2 \mathrm{~mm}$. with a thick wall and practically no lumen.

In a few cases, middle cerebral aneurysms which had been wrapped in cotton gauze, months or years previously, could be examined histologically. They had the appearance of a fibrous mass into which the middle cerebral artery passed and its branches emerged at the other side. There was some fibrous thickening of the intima of these vessels within the mass but they were not occluded. The wall of the aneurysms was very thick and collagenous and only a small lumen was in continuity with the parent vessel. This wall merged into tissue showing a fibrous foreign body giant cell reaction containing small fragments of the disintegrating gauze.

\section{DISCUSSION}

Recurrent haemorrhage within two or three weeks is the greatest danger confronting the patient who has survived one haemorrhage from an aneurysm. It would be useful to be able to predict on angiographic grounds which aneurysms were most likely to rupture again soon. An attempt has been made to do this, but it is doubtful if the information obtained would stand up to the test of clinical application to the individual patient; the findings, however, are not without interest.

Posterior communicating aneurysms were found in this series to give rise to these early recurrent haemorrhages rather more often than other aneurysms. It is doubtful if these recurrent haemorrhages were more lethal than those from other aneurysms. It may be that their site in a basal cistern results in a less closely applied mass of platelets, fibrin, arachnoid strands, and pial membrane than develops with anterior communicating and middle cerebral aneurysms, which are intimately enclosed in cerebral fissures.

Multiloculation was found to be of no assistance in predicting recurrent haemorrhage from an aneurysm, while the presence of partial or even extensive thrombosis within an aneurysm afforded no guarantee against early recurrence. The histological findings suggested that blood does in fact dissect up between thrombus and aneurysm wall in some cases to break out again through the original point of rupture (Crawford, 1959b).
The larger, more globular or pyriform aneurysms seem more likely to rupture again soon than the smaller, longer, and more tubular aneurysms, possibly because the tension in the wall of a globular or pyriform aneurysm is greater than that in the wall of a long, tubular aneurysm of the same volume.

Comparison of different surgical procedures showed that recurrent haemorrhage occurred surprisingly seldom through the cotton gauze wrapping placed around some of the aneurysms. This appears to be a good early prophylactic measure, in view of its ease and lack of trauma to near-by vessels, which were seldom obliterated as a result. It appears to be more important in preventing recurrent haemorrhage by encouraging thrombus formation and fibrosis around rather than within an aneurysm. A thick fibrous wall is soon acquired by the aneurysm, which must virtually guarantee against the occurrence of one of the rarer late recurrent haemorrhages. Obliteration of one anterior cerebral stem, usually the one filling the aneurysm on angiography, did not appear to be highly effective in preventing recurrent haemorrhage from anterior communicating aneurysms. If the blood flow through the unclipped anterior cerebral stem was sufficient to prevent infarction in the anterior cerebral distribution, then the pulse pressure transmitted by it also appeared adequate to produce recurrent haemorrhage from the anterior communicating aneurysm. Most of the common carotid ligations performed for ruptured posterior communicating aneurysms were effective in preventing recurrent haemorrhages, but those for anterior communicating aneurysms were not effective, presumably because these distal aneurysms were not protected from the pulsatile flow from the collaterals on the opposite side. Observations on two cases confirmed that proximal occlusion of a feeding artery, as in carotid ligation, does sometimes eventually lead to sclerosis and shrinkage of not too distally situated aneurysms (Harrison, Odom, and Kunkle, 1963). This may be by the reduction of pulsation or mural thrombosis or both.

\section{SUMMARY}

Recurrent haemorrhage within six weeks of the haemorrhage necessitating admission occurred in about a half of those cases not receiving surgery. They were slightly more frequent with posterior communicating and anterior choroidal aneurysms.

There was little difference in the age and sex distribution of cases which had had and those which had not had recurrent haemorrhages.

Recurrent haemorrhages were no more frequent with multiloculated than with uniloculated aneurysms. 
The ruptures in the aneurysms were sealed by a laminated platelet and fibrin thrombus, suggesting that platelet conglutination was an important factor in terminating haemorrhage from an aneurysm.

Recurrent haemorrhages occurred through the original rupture. Partial or even near-total thrombosis of an aneurysm did not guarantee against early recurrent haemorrhage, which burst through the thrombus or dissected up between it and the wall of the aneurysm.

The larger and the more globular aneurysms appeared more likely to suffer early recurrent haemorrhage than the smaller and the longer aneurysms.

Vascular hypertension was no more common in cases with recurrent haemorrhage than in those without.

In cases with multiple aneurysms early recurrent haemorrhage was always from the same aneurysm as originally ruptured.

The effects of surgery on early recurrent haemorrhage were examined. Wrapping the aneurysm in cotton gauze was notably effective and recurrent haemorrhage occurred very seldom. Clipping the dominant anterior cerebral stem and common carotid ligation for anterior communicating aneurysms were not very effective, but common carotid ligation was effective for posterior communicating aneurysms. In two cases, proximal occlusion of the parent artery was seen to result in shrinkage and sclerosis of the aneurysm. Wrapping with gauze resulted in a foreignbody giant cell reaction with eventual dense sclerosis and thickening of the aneurysm wall.

My thanks are due to the Wolfson Foundation and to the National Institute of Health, Bethesda, Maryland, 0 U.S.A., for grants which made this study possible. I am also indebted to Professor T. Crawford of the Department of Pathology at St. George's Hospital, and Mr. Wylie McKissock, Mr. L. S. Walsh, and Mr. A. E. Richardson, of the Neurosurgical Department of St. $\vec{F}$ George's Hospital at Atkinson Morley's Hospital, Wimbledon, for their interest, encouragement, and skilled criticism. My thanks are finally due to the technical, photographic, and secretarial staff whose assistance was invaluable.

\section{REFERENCES}

Crawford, T. (1959a). Intracranial aneurysms-pathological aspects. Brit. J. Radiol., 32, 84.

- (1959b). Some observations on the pathogenesis and natural history of intracranial aneurysms. J. Neurol. Neurosurg. Psychiat., 22, 259-266.

Crompton, M. R. (1962). Intracerebral haematoma complicating ruptured cerebral berry aneurysm. Ibid., 25, 378-386.

McKissock, W. (1956). Subarachnoid haemorrhage. Ann. roy. Colt Surg. Engl., 19, 361-370.

-, Paine, K. W. E., and Walsh, L. S. (1960). An analysis of the results of treatment of ruptured intracranial aneurysms. Repoch of 772 consecutive cases. $J$. Neurosurg., 17, 762-776.

Harrison, T. H., Odom, G. L., and Kunkle, E. C. (1963). Interna电 carotid aneurysm arising in carotid canal. Arch. Neurof (Chic.), 8, 328-331. 